\title{
Clinical and Pulmonary Function Markers of Respiratory Exacerbation Risk in Subjects With Quadriplegic Cerebral Palsy
}

\author{
Andrea Vianello MD, Elena Carraro MD, Emanuela Pipitone PhD, Rosario Marchese-Ragona MD, \\ Giovanna Arcaro MD, Marco Ferraro MD, Luciana Paladini MD, and Andrea Martinuzzi MD
}

\begin{abstract}
BACKGROUND: Although respiratory exacerbations are common in patients with quadriplegic cerebral palsy (CP), little is known about the factors that are related to increased exacerbation risk. This study aimed to identify the clinical and pulmonary function variables signaling risk of exacerbation in this type of patient. METHODS: Thirty-one children and young adults with quadriplegic CP underwent a comprehensive history, physical examination, and pulmonary function test, including arterial blood gas analysis, airway resistance using the interrupter technique, and home overnight $\mathrm{S}_{\mathrm{pO}_{2}}$ monitoring. Subjects were divided into 2 groups depending on the number of respiratory exacerbations reported during the year before study entry: frequent exacerbators (ie, $\geq 2$ exacerbations) and infrequent exacerbators (ie, $<2$ exacerbations). RESULTS: The frequent exacerbators were more likely to require hospitalization due to respiratory disorders compared with the infrequent exacerbators $(13 / 14 \mathrm{vs} 9 / 17, P=.02)$. Respiratory exacerbation was found to be associated with diagnosis of gastroesophageal reflux (adjusted odds ratio of 23.95 for subjects with confirmed diagnosis, $P=.02$ ) and higher $\mathrm{P}_{\mathrm{aCO}}$ levels (adjusted odds ratio of 12.60 for every 5 -mm $\mathrm{Hg}$ increase in $\mathbf{P}_{\mathrm{aCO}_{2}}, P=.05$ ). Subjects with $\mathbf{P}_{\mathrm{aCO}_{2}} \geq 35 \mathrm{~mm} \mathrm{Hg}$ showed an exacerbation odds ratio of $15.2(95 \%$ CI 1.5-152.5, $P=.01)$. CONCLUSIONS: Gastroesophageal reflux and increased $\mathbf{P}_{\mathrm{aCO}}$, can be considered simple, clinically useful markers of increased exacerbation risk in young subjects with quadriplegic CP. Key words: cerebral palsy; respiratory exacerbation; arterial blood gases; gastroesophageal reflux; pulmonary function test; pulmonary rehabilitation. [Respir Care 2015;60(10):1431-1437. (c) 2015 Daedalus Enterprises]
\end{abstract}

\section{Introduction}

Cerebral palsy (CP) has been defined as a disorder resulting from non-progressive injury to the motor-control areas of the developing brain. Affecting 2-6 infants in 1,000 births, it is considered the most common physical disability in childhood resulting in multisystem medical problems. ${ }^{1,2}$

Although seizures and disturbances in motor control, cognition, communication, perception, and behavior are

\footnotetext{
Drs Vianello, Arcaro, Ferraro, and Paladini are affiliated with the Respiratory Pathophysiology Division, City Hospital of Padova, Padova, Italy. Drs Carraro and Martinuzzi are affiliated with the Neuropediatric Rehabilitation Unit, E Medea Scientific Institute, Conegliano, Italy. Dr Pipitone is affiliated with the Department of Formative Sciences, University of Modena and Reggio Emilia, Modena, Italy. Dr MarcheseRagona is affiliated with the Department of Neurosciences, Otolaryngology Unit, University of Padova, Padova, Italy.
}

the most common features of the disorder, respiratory complications are of concern to a significant proportion of severely disabled patients with $\mathrm{CP}$ and represent a major cause of morbidity and mortality. ${ }^{3-7}$ Patients with $\mathrm{CP}$ are often vulnerable to respiratory complications that can lead to exacerbation. Identifying reliable markers of exacerbation risk could aid physicians in making timely decisions about patient care and recommendations with regard to pulmonary rehabilitation programs.

\footnotetext{
This study was supported in part by a grant from the Associazione Padovana per la Riabilitazione dell'Insufficienza Respiratoria (APRIR). The authors have disclosed no conflicts of interest.
}

Correspondence: Andrea Vianello MD, UO id Fisiopatologia Respiratoria, Azienda Ospedaliera di Padova, Via Giustiniani 2, 35128 Padova, Italy. E-mail: avianello@qubisoft.it.

DOI: $10.4187 /$ respcare. 04024 
Respiratory exacerbation can be defined as a sustained worsening of the patient's respiratory condition that goes beyond normal day-to-day variations with respect to his or her usual stable state; acute in onset, it necessitates the use of antibiotics. ${ }^{8}$ Consistent with the exacerbation definition proposed by the COPD Workshop, the beyond normal day-to-day variation wording reflects the fact that a patient's stable state may fluctuate. ${ }^{9}$ Respiratory exacerbations have been found to be one of the leading causes of hospitalization in subjects with $\mathrm{CP}$, accounting for $13 \%$ of admissions for children and $16 \%$ for young adults. ${ }^{10}$ They are also the immediate cause of death in $\sim 40 \%$ of children with spastic quadriplegia, produce severe distress and poorer health status, and impose a substantial burden on caregivers. ${ }^{6,7,11-13}$

Several factors can potentially contribute to the development of respiratory exacerbation in patients with $\mathrm{CP}$, including ineffective cough with airway mucus encumbrance, inability to handle oropharyngeal secretions, swallowing disorders, and gastroesophageal reflux, all conditions that can lead to an increased risk of pulmonary aspiration. In addition, inadequate nasopharyngeal motor tone causing upper-airway obstruction and obstructive sleep apnea syndrome, scoliosis deformities leading to obstruction of the lower-lobe bronchi, and poor nutritional status may further compromise respiratory function. ${ }^{14,15}$

Previous studies have reported that comprehensive pulmonary rehabilitation programs, including regular assessment of respiratory status, chest physical therapy to assist airway clearance, and home noninvasive ventilation to manage sleep-disordered breathing, can significantly improve pulmonary function and sleeping patterns in subjects with $\mathrm{CP}$, reducing exacerbations and the need for hospitalization. ${ }^{14,16,17}$ Identifying the patients who are at an increased risk of developing respiratory complications and thus more likely to benefit from pulmonary rehabilitation could improve timely treatment/rehabilitation for those most in need. Selecting appropriate candidates for pulmonary rehabilitation programs is particularly important, as these are costly and time-consuming, both relevant considerations for families already burdened with caring for a disabled child.

The literature investigating clinical and pulmonary function markers that identify subjects with $\mathrm{CP}$ at increased risk of developing respiratory complications is disappointingly scarce, and findings vary considerably from study to study. Pulmonary aspiration syndrome, which is signaled by a positive salivagram or barium videofluoroscopy test, has been found to be a useful marker of high exacerbation risk. ${ }^{16}$ Other studies have demonstrated that both decreased chest-wall motility and reduced respiratory-muscle strength are sensitive markers of poor respiratory outcome. ${ }^{18}$ The paucity of information on this topic prompted us to investigate what single factor or combination of factors may

\section{QUICK LOOK}

\section{Current knowledge}

Cerebral palsy $(\mathrm{CP})$ is a disorder resulting from nonprogressive injury to the motor-control areas of the developing brain. Although seizures and disturbances in motor control, cognition, communication, perception, and behavior are the most common features, respiratory complications represent a major cause of morbidity and mortality. Markers that identify patients with $\mathrm{CP}$ who are at an increased risk of developing respiratory complications have not been fully elucidated.

\section{What this paper contributes to our knowledge}

Gastroesophageal reflux and increased $\mathrm{P}_{\mathrm{aCO}}$ proved to be clinically useful markers of increased exacerbation risk in young subjects with quadriplegic CP. $\mathrm{A}_{\mathrm{aCO}_{2}}$ of $>35 \mathrm{~mm} \mathrm{Hg}$ was associated with an increased risk of pulmonary exacerbation. For every increase in $\mathrm{P}_{\mathrm{aCO}_{2}}$ of $5 \mathrm{~mm} \mathrm{Hg}$, the adjusted odds ratio for developing an exacerbation was 12.6 (95\% CI 1.03-154.33).

signal an increased risk of respiratory exacerbations in subjects with quadriplegic $\mathrm{CP}$.

\section{Methods}

The association between increased respiratory exacerbation and anthropometric, clinical, and/or pulmonary function variables was investigated in a group of 31 children and young adults with spastic quadriplegic $\mathrm{CP}$ consecutively admitted to the Neuropediatric Rehabilitation Unit of the E Medea Scientific Institute in Conegliano, Italy. The study was approved by the institutional review board. The subjects' parents or guardians gave written informed consent for participation in this study.

\section{Subjects}

All consecutive patients affected with spastic quadriplegic CP and admitted to the E. Medea Scientific Institute Neuropediatric Rehabilitation Unit for scheduled medical checkups between January 1, 2011, and December 31, 2013, were considered potential subjects for this study. Subjects were referred either by their primary care physicians or physiatrists.

According to the subjects' medical records, the diagnosis of spastic quadriplegic CP was based on clinical assessment, presence of bilateral spasticity of all extremities, severe intellectual disability, and seizures. All subjects had previously undergone magnetic resonance imaging to rule 
out a diagnosis of hereditary neurodegenerative disease. The exclusion criteria were: diagnosis of a genetic, neurologic, or metabolic disease that could impair brain development; intrinsic lung disease such as bronchopulmonary dysplasia or cystic fibrosis that could influence outcome measures; and participation in a pulmonary rehabilitation program on a regular basis. Disease severity was assessed according to the Gross Motor Function Classification System. ${ }^{19}$

\section{Measures}

All subjects underwent a comprehensive history and physical examination at study entry. Anthropometric measurements, including standard body mass index (BMI), were calculated for all subjects. ${ }^{20}$ In addition, BMI Z scores were calculated for subjects who were $<21 \mathrm{y}$ old; all subjects were classified as underweight, normal, overweight, or obese depending on their BMI or BMI Z score. Arm span was used to calculate height in subjects with severe scoliosis. The number of respiratory exacerbations during the year preceding the study, as defined by the exacerbation definition proposed by the COPD Workshop, was recorded. ${ }^{9}$ A differential diagnosis between pneumonia and any other respiratory tract infection causing an exacerbation was not feasible, as information available in subjects' medical records was deemed inadequate. The following were carefully assessed: number of respiratoryrelated admissions to acute care hospitals during the year preceding the study; presence of gastroesophageal reflux, as defined by a 24-h $\mathrm{pH}$ monitoring test performed using an antimony $\mathrm{pH}$ electrode and indicating $>7 \%$ of the total time at $\mathrm{pH}<4$ in the lower esophagus, which was conducted within $\sim 2$ y of the study's initiation ${ }^{21}$; presence of fluid aspiration in the airway, as defined by a positive salivagram or barium videofluoroscopy test conducted within $\sim 2$ y of the study's initiation ${ }^{22}$; previous anti-reflux surgical procedure (Nissen fundoplication); presence of a gastrostomy or gastrojejunostomy tube and subject's feeding pattern after tube placement; presence of scoliosis, as defined by a clinical examination and/or anteroposterior radiographs of the spine; long-term use of spinal bracing; airway mucus encumbrance, defined as the coexistence of auscultatory ronchi and oxyhemoglobin desaturation (arterial oxygen saturation of $<95 \%)^{23}$; presence of a tracheostomy tube; and use of anticonvulsant medication.

Following enrollment, all subjects underwent a pulmonary function evaluation, including arterial blood gas analysis performed on blood samples taken from earlobe capillaries while the subject spontaneously breathed room air (RAPIDPoint 405 blood gas analysis system, Siemens, Munich, Germany). To ensure good blood circulation, the ear lobe was warmed before the puncture. Sampling of arterialized capillary blood was preferred to arterial puncture or catheterization because it is technically simpler and less likely to result in serious complications; research has shown that this method provides sufficiently accurate measurements of $\mathrm{P}_{\mathrm{aO}_{2}}$ and $\mathrm{P}_{\mathrm{aCO}}{ }_{2}{ }^{24}$ Airway resistance was measured by the interrupter technique; this simple test, which requires only passive cooperation, provides an accurate estimate of airway resistance. ${ }^{25}$ Home overnight $\mathrm{S}_{\mathrm{pO}_{2}}$ monitoring was performed within 3 nights of entering the study. After data acquisition, artifact-free sequences were identified using data analysis software (8500 handheld pulse oximeter, Nonin, Plymouth, Minnesota). Sleep-disordered breathing was considered clinically important when an $\mathrm{S}_{\mathrm{pO}_{2}}$ nadir of $<92 \%$ or an oxygen desaturation index (average number of desaturation episodes/h) of $>1$ was detected. ${ }^{26}$

Subjects were divided into 2 groups depending on the number of respiratory exacerbations reported during the year before the study. The frequent-exacerbator group included those subjects whose parents reported 2 or more exacerbation episodes during the year before the study. The infrequent-exacerbator group included those subjects who experienced $<2$ exacerbation episodes during that time. The cutoff of 2 episodes/y is consistent with that used for patients with COPD, a condition that is characterized by a similar fluctuating respiratory course and a gradual decrease in the patient's overall status. ${ }^{9}$

\section{Statistical Analysis}

Continuous variables are reported as mean $\pm \mathrm{SD}$, and categorical variables are listed as percentages. Normality of variable distribution was tested using the KolmogorovSmirnov test. An unpaired Student $t$ test was used to compare continuous variables with normal distribution; nonnormally distributed variables were compared using the Wilcoxon rank-sum test. Categorical variables were compared using the chi-square test or the Fisher exact test as appropriate.

Risk factors for respiratory exacerbation were analyzed using the logistic regression model. The variables showing $P<.1$ on univariate analysis were used as predictive independent variables in multivariate logistic regression. Unadjusted and adjusted odds ratios and 95\% CI were reported for variables included in multivariate logistic regression. Model calibration was assessed according to the Hosmer-Lemeshow test. The best cutoff for the continuous $\mathrm{P}_{\mathrm{aCO}}$ variable was found by receiver operating characteristic curve analysis using the Youden index and was used for dichotomizing the subjects. $P<.05$ was considered statistically significant. Statistical analysis was performed using SAS 9.2 (SAS Institute, Cary, North Carolina). 
Respiratory Exacerbation Risk in Quadriplegic Cerebral Palsy

Table 1. Subjects' Anthropometric and Clinical Data at Study Entry

\begin{tabular}{|c|c|c|c|c|}
\hline Data & All Subjects & Frequent Exacerbators & Infrequent Exacerbators & $P$ \\
\hline Subjects, $n$ & 31 & 14 & 17 & NA \\
\hline Age, mean $\pm \mathrm{SD}$ y & $13.0 \pm 7.7$ & $13.3 \pm 8.7$ & $12.7 \pm 7.07$ & $.97 *$ \\
\hline Sex, $n(\%)$ & & & & $.92 \dagger$ \\
\hline Males & $18(58)$ & $8(57.1)$ & $10(58.8)$ & \\
\hline Females & $13(42)$ & $6(42.9)$ & $7(41.2)$ & \\
\hline $\mathrm{BMI}$, mean $\pm \mathrm{SD} \mathrm{kg} / \mathrm{m}^{2}$ & $14.88 \pm 3.1$ & $15.86 \pm 3.3$ & $14.19 \pm 2.86$ & $.17 \ddagger$ \\
\hline Underweight, $n(\%)$ & $17(54.8)$ & $5(35.7)$ & $13(76.5)$ & $.1 \S$ \\
\hline Exacerbations during preceding $\mathrm{y}$, mean $\pm \mathrm{SD}$ & $2.29 \pm 1.69$ & $4.00 \pm 0.88$ & $0.88 \pm 0.33$ & $<.001 *$ \\
\hline Hospitalized during preceding year, $n(\%)$ & $22(71.0)$ & $13(92.9)$ & $9(52.9)$ & $.02 \S$ \\
\hline Gastroesophageal reflux, $n(\%)$ & $8(25.8)$ & $6(42.8)$ & $2(11.8)$ & $.09 \S$ \\
\hline Dysphagia, $n(\%)$ & $24(77.4)$ & $11(78.6)$ & $13(76.5)$ & $>.99$ \\
\hline Gastric fundoplication, $n(\%)$ & $9(29)$ & $2(14.2)$ & $7(41.2)$ & $.67 \S$ \\
\hline Gastrostomy tube, $n(\%)$ & $11(35.5)$ & $7(50)$ & $4(23.5)$ & $.15 \S$ \\
\hline Scoliosis, $n(\%)$ & $11(35.5)$ & $4(28.6)$ & $7(41.2)$ & $.7 \S$ \\
\hline Spinal bracing, $n(\%)$ & $13(42)$ & $4(28.6)$ & $9(52.9)$ & $.17 \dagger$ \\
\hline Airway mucus encumbrance, $n(\%)$ & $16(51.6)$ & $10(71.4)$ & $6(35.3)$ & $.07 \S$ \\
\hline Tracheostomy tube, $n(\%)$ & $2(6.4)$ & $2(14.3)$ & $0(0)$ & $.2 \S$ \\
\hline Receiving anticonvulsant medication, $n(\%)$ & $19(61.3)$ & $9(64.3)$ & $10(58.8)$ & $.75 \dagger$ \\
\hline 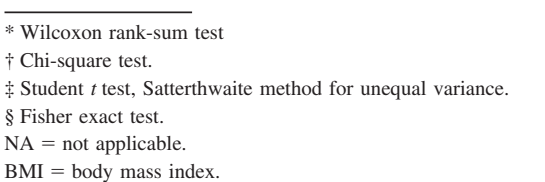 & & & & \\
\hline
\end{tabular}

\section{Results}

During the study period (January 1, 2011, to December 31, 2013), 37 consecutive children and young adults suffering from spastic quadriplegic $\mathrm{CP}$ were considered for eligibility to participate in our study. Six were excluded, as the clinical data that were available were very limited. All subjects were classified as level V according to the Gross Motor Function Classification System.

Fourteen were assigned to the frequent-exacerbator group and 17 to the infrequent-exacerbator group. Subjects' baseline anthropometric and clinical characteristics are outlined in Table 1. Subjects with gastrostomy or gastrojejunostomy tubes were fed exclusively by the probe, although mothers reported a strong resistance to accepting this kind of feeding. The frequent exacerbators differed from the infrequent exacerbators in that they showed a higher exacerbation rate $(4.00 \pm 0.88$ vs $0.88 \pm 0.33, P<.001)$ and were more likely to require hospitalization due to respiratory causes $(13 / 14$ vs $9 / 17, P=.02)$. They also demonstrated a tendency toward a higher frequency of airway mucus encumbrance $(10 / 14$ vs $6 / 17, P=.07)$ and gastroesophageal reflux $(6 / 14$ vs $2 / 17, P=.10)$.

The subjects' baseline pulmonary function and blood gas data are provided in Table 2. All of the children were able to successfully undergo airway resistance measurement. The frequent exacerbators had significantly higher levels of $\mathrm{P}_{\mathrm{aCO}}$ compared with the infrequent exacerbators ( $35 \pm 6$ vs $31 \pm 3 \mathrm{~mm} \mathrm{Hg}, P=.04$ ).

According to multivariate logistic regression, respiratory exacerbation was associated with gastroesophageal reflux $(P=.02)$ with an adjusted odds ratio of 23.95 (95\% CI 1.58-363.86). It was also associated with $\mathrm{P}_{\mathrm{aCO}_{2}}$ $(P=.05)$ with an adjusted odds ratio of 12.60 (95\% CI 1.03154.33) for every 5-mm Hg increase in $\mathrm{P}_{\mathrm{aCO}}$. The logistic regression model showed adequate goodness of fit $(P=.84)$. In addition, the subjects with $\mathrm{P}_{\mathrm{aCO}_{2}} \geq 35 \mathrm{~mm} \mathrm{Hg}$ showed an odds ratio of exacerbation of 15.2 (95\% CI 1.5$152.5, P=.01)$; this cutoff showed a sensitivity of $53.9 \%$, a specificity of $92.9 \%$, and an area under the curve of $71.7 \%(P=.04)$. None of the other covariates had a significant effect on respiratory exacerbation. Data from the logistic regression analysis are provided in Table 3.

\section{Discussion}

Consistent with previous reports that respiratory complications appear to be the most common comorbidity in young subjects with $\mathrm{CP}, 7,10 \sim 45 \%$ of our study population showed a high exacerbation rate ( $\geq 2$ episodes/y). A relevant proportion of the subjects being studied $(22 / 31,71 \%)$ required, in addition, admission to acute care hospitals due to respiratory disorders during the year before the study. Finding a high hospitalization rate among subjects with 
Table 2. Pulmonary Function and Blood Gas Data at Study Entry

\begin{tabular}{|c|c|c|c|c|}
\hline Parameter & All Subjects & Frequent Exacerbators & Infrequent Exacerbators & $P$ \\
\hline $\mathrm{pH}$ & $7.48 \pm 0.06$ & $7.48 \pm 0.06$ & $7.47 \pm 0.07$ & $.83^{*}$ \\
\hline $\mathrm{P}_{\mathrm{aO}_{2}}, \mathrm{~mm} \mathrm{Hg}$ & $81 \pm 24$ & $75 \pm 22$ & $86 \pm 24$ & $.2 *$ \\
\hline $\mathrm{P}_{\mathrm{aCO}_{2}}, \mathrm{~mm} \mathrm{Hg}$ & $33 \pm 5$ & $35 \pm 6$ & $31 \pm 3$ & $.04 *$ \\
\hline $\mathrm{S}_{\mathrm{aO}_{2}}, \%$ & $95 \pm 4$ & $94 \pm 4$ & $96 \pm 4$ & $.2 \dagger$ \\
\hline \multicolumn{5}{|l|}{ Interrupter technique, $\mathrm{cm} \mathrm{H}_{2} \mathrm{O} / \mathrm{L} / \mathrm{s}$} \\
\hline Inspiratory airway resistance & $13.97 \pm 5.71$ & $13.76 \pm 6.22$ & $14.07 \pm 5.40$ & $.89 *$ \\
\hline Expiratory airway resistance & $12.85 \pm 4.28$ & $13.15 \pm 5.20$ & $12.64 \pm 3.67$ & $.7 *$ \\
\hline $\mathrm{SDB}, n(\%)$ & $10(32.1)$ & $3(21.4)$ & $7(41.2)$ & .28 \\
\hline \multicolumn{5}{|c|}{$\begin{array}{l}\text { Data are expressed as mean } \pm \mathrm{SD} \text { unless indicated otherwise. } \\
\text { * Student } t \text { test, Satterthwaite method for unequal variance. } \\
\dagger \text { Wilcoxon rank-sum test. } \\
\ddagger \text { Fisher exact test. } \\
\mathrm{S}_{\mathrm{aO}}=\text { arterial oxygen saturation. } \\
\mathrm{SDB}=\text { sleep-disordered breathing. }\end{array}$} \\
\hline
\end{tabular}

Table 3. Unadjusted and Adjusted Odds Ratios and 95\% CI From Univariate and Multivariate Logistic Regression Analyses of Respiratory Exacerbation Risk

\begin{tabular}{|c|c|c|c|c|c|c|}
\hline Variable & Odds Ratio & $95 \% \mathrm{CI}$ & $P$ & Adjusted Odds Ratio* & $95 \% \mathrm{CI}$ & $P$ \\
\hline Gastroesophageal reflux & 5.63 & $0.92-34.57$ & $.09 \dagger$ & 23.95 & $1.58-363.86$ & .02 \\
\hline $\mathrm{P}_{\mathrm{aCO}_{2}}(\Delta=5 \mathrm{~mm} \mathrm{Hg})$ & 3.10 & $0.92-10.39$ & .07 & 12.60 & $1.03-154.33$ & .05 \\
\hline Airway mucous encumbrance & 4.58 & $0.99-21.12$ & $.07 \dagger$ & 7.26 & $0.38-137.44$ & .18 \\
\hline
\end{tabular}

$\mathrm{CP}$, Young et al ${ }^{27}$ likewise reported that the children and young adults they were studying were admitted to acute care hospitals 7 times more often than age-matched peers. Mahon and Kibirige ${ }^{11}$ emphasized the importance of upper- and/or lower-respiratory-tract infections, which accounted in their study for up to $42 \%$ of hospital admissions.

The consequences of respiratory complications in patients with $\mathrm{CP}$ in terms of health status, life expectancy, and quality of life and the need for frequent, costly hospitalizations have made identifying clinical and/or pulmonary function variables signaling respiratory exacerbation risk even more urgent. This information can aid physicians in making timely decisions about patient care and management.

When subject characteristics associated with high exacerbation rate were examined, we found that diagnosis of gastroesophageal reflux was linked to increased exacerbation frequency. Subjects with gastroesophageal reflux were found to have a substantially higher risk of exacerbation ( $>23$-fold) compared with the others. Gastroesophageal reflux is commonly found in infants and children with developmental delay and, in particular, in patients with CP. Considered a multifactorial disorder, gastroesophageal reflux may be linked to a combination of elements, including a central nervous system dysfunction affecting lower-esophageal-sphincter continence; presence of a hiatal hernia; prolonged supine position; and increased intraabdominal pressure secondary to spasticity, scoliosis, constipation, and/or seizures. ${ }^{21,28-30}$

As a consequence of gastric content aspiration, gastroesophageal reflux is a well-known cause of recurrent pneumonia and interstitial lung disease and a contributing factor to the onset of asthma symptoms in pediatric populations. Its severity in patients with CP may be worse, as it could be linked to poor self-protective mechanisms, in particular, ineffective cough and swallowing, as well as to delayed diagnosis due to difficulties in obtaining an accurate history and physical examination. ${ }^{21}$

Our results have led us to speculate, although we do not have direct data as proof, that gastroesophageal reflux contributes to an increased exacerbation frequency in children with $\mathrm{CP}$ by causing aspiration into the lower airways. Given the efficacy of Nissen fundoplication in treating gastroesophageal reflux-related digestive and respiratory disturbances in chronically ill children, ${ }^{31-33}$ it probably seems counterintuitive that, in our experience, subjects undergoing this type of anti-reflux surgery show no significant improvement: their exacerbation risk is similar to that of subjects who have not undergone the procedure. 
Indeed, the results of our study agree with previous data demonstrating that Nissen fundoplication does not lead to improvement in respiratory disturbances in $\sim 50 \%$ of neurologically impaired children. ${ }^{31}$ Further studies are needed to elucidate the association between gastroesophageal reflux and respiratory exacerbation and the utility of Nissen fundoplication in this patient population.

Among studies aiming to identify the most common factors related to pulmonary exacerbation risk in subjects with $\mathrm{CP}$, ours is probably the first that has highlighted an association between exacerbation risk and $\mathrm{P}_{\mathrm{aCO}_{2}}$ : subjects presenting with higher $\mathrm{P}_{\mathrm{aCO}}$ had a worse prognosis. In particular, our results show that there is an $\sim 12$-fold increase in risk for every 5-mm $\mathrm{Hg}$ increment in $\mathrm{P}_{\mathrm{aCO}}$ and a 15 -fold increase in risk above the $35-\mathrm{mm} \mathrm{Hg}$ cutoff threshold. In view of the fact that a tendency toward low baseline $\mathrm{P}_{\mathrm{aCO}}(33.11 \pm 5.12 \mathrm{~mm} \mathrm{Hg})$ was observed in our entire population and that $\mathrm{P}_{\mathrm{aCO}}$ is the marker of alveolar ventilation, we speculate that patients with $\mathrm{CP}$ tend to hyperventilate during spontaneous breathing and that this breathing pattern may occur at least in part to compensate for low-baseline oxygenation. In our study group, $\mathrm{P}_{\mathrm{aO}_{2}}$ (mean of $81.07 \pm 23.50 \mathrm{~mm} \mathrm{Hg}$ ) approximated the lowest limit defining normal oxygenation in children, that is $80 \mathrm{~mm} \mathrm{Hg.}{ }^{24}$ In this context, higher $\mathrm{P}_{\mathrm{aCO}}$ in patients with high exacerbation risk may be linked to an attenuated ventilatory response to the metabolic demand of $\mathrm{O}_{2}$ consumption. Taking this hypothesis a step further, we speculate that diminished ventilatory response may predispose patients to development of clinically relevant exacerbations due to a failure to compensate for an increased ventilatory demand. ${ }^{34}$

Our study is not without some limitations. First, the definition adopted for pulmonary exacerbation was an arbitrary one. It is nevertheless true that the criteria and the extent to which fluctuations in respiratory status in children with CP should be considered within and outside the normal range of variation have yet to be clearly established. Second, although the technique for sampling earlobe arterialized blood is well established and routinely utilized in several laboratories, our measurements could have been influenced by methodological factors, in particular, suboptimal vasodilatation. ${ }^{35}$

\section{Conclusions}

Despite its limitations, the study does provide useful information for physicians caring for quadriplegic patients with $\mathrm{CP}$. We have provided new and unequivocal evidence that exacerbation risk is markedly associated with gastroesophageal reflux and increased $\mathrm{P}_{\mathrm{aCO}_{2}}$. We hope that these findings will lead the way to a clearer path for physicians assisting children and young adults afflicted with quadri- plegic $\mathrm{CP}$ and furnish new ideas for further research on this topic.

\section{REFERENCES}

1. Stempien LM, Gaebler-Spira D. Rehabilitation of children and adults with cerebral palsy. In: Braddom RL. Physical medicine and rehabilitation, 2nd edition. Philadelphia: WB Saunders; 2000; 1191-1212.

2. Bax M, Goldstein M, Rosenbaum P, Leviton A, Paneth N, Dan B, et al. Proposed definition and classification of cerebral palsy. Dev Med Child Neurol 2005;47(8):571-576.

3. Evans PM, Alberman E. Certified cause of death in children and young adults with cerebral palsy. Arch Dis Child 1991;66(3):325329.

4. Maudsley G, Hutton JL, Pharoah PO. Cause of death in cerebral palsy: a descriptive study. Arch Dis Child 1999;81(5):390-394.

5. Hutton JL, Colver AF, Mackie PC. Effect of severity of disability on survival in north east England cerebral palsy cohort. Arch Dis Child 2000;83(6):468-474.

6. Reddihough DS, Baikie G, Walstab JE. Cerebral palsy in Victoria, Australia: mortality and causes of death. J Paediatr Child Health 2001;37(2):183-186.

7. Duruflé-Tapin A, Colin A, Nicolas B, Lebreton C, Dauvergne F, Gallien P. Analysis of the medical causes of death in cerebral palsy. Ann Phys Rehabil Med 2014;57(1):24-37.

8. Sullivan PB, Morrice JS, Vernon-Roberts A, Grant H, Eltumi M, Thomas AG. Does gastrostomy tube feeding in children with cerebral palsy increase the risk of respiratory morbidity? Arch Dis Child 2006;91(6):478-482.

9. Rodriguez-Roisin R. Toward a consensus definition for COPD exacerbations. Chest 2000;117(5 Suppl 2):398S-401S

10. Young NL, McCormick AM, Gilbert T, Ayling-Campos A, Burke T, Fehlings D, Wedge J. Reasons for hospital admissions among youth and young adults with cerebral palsy. Arch Phys Med Rehabil 2011; 92(1):46-50.

11. Mahon M, Kibirige MS. Patterns of admissions for children with special needs to the paediatric assessment unit. Arch Dis Child 2004; 89(2):165-169.

12. Murphy NA, Hoff C, Jorgensen T, Norlin C, Young PC. Costs and complications of hospitalizations for children with cerebral palsy. Pediatr Rehabil 2006;9(1):47-52.

13. Liptak GS. Health and well being of adults with cerebral palsy. Curr Opin Neurol 2008;21(2):136-142.

14. Toder DS. Respiratory problems in the adolescent with developmental delay. Adolesc Med 2000;11(3):617-631.

15. Strauss D, Brooks J, Rosenbloom L, Shavelle R. Life expectancy in cerebral palsy: an update. Dev Med Child Neurol 2008;50(7):487493.

16. Fitzgerald DA, Follett J, Van Asperen PP. Assessing and managing lung disease and sleep disordered breathing in children with cerebral palsy. Paediatr Respir Rev 2009;10(1):18-24.

17. Lee HY, Cha YJ, Kim K. The effect of feedback respiratory training on pulmonary function of children with cerebral palsy: a randomized controlled preliminary report. Clin Rehabil 2014;28(10):965-971.

18. Wang HY, Chen CC, Hsiao SF. Relationships between respiratory muscle strength and daily living function in children with cerebral palsy. Res Dev Disabil 2012;33(4):1176-1782.

19. Palisano R, Rosenbaum P, Walter S, Russell D, Wood E, Galuppi B. Development and reliability of a system to classify gross motor function in children with cerebral palsy. Dev Med Child Neurol 1997;39(4):214-223.

20. Berkey CS, Colditz GA. Adiposity in adolescents: change in actual BMI works better than change in BMI $\mathrm{z}$ score for longitudinal studies. Ann Epidemiol 2007;17(1):44-50. 


\section{Respiratory Exacerbation Risk in Quadriplegic Cerebral Palsy}

21. Vandenplas Y, Rudolph CD, Di Lorenzo C, Hassall E, Liptak G, Mazur L, et al. Pediatric gastroesophageal reflux clinical practice guidelines: joint recommendations of the North American Society for Pediatric Gastroenterology, Hepatology, and Nutrition (NASPGHAN) and the European Society for Pediatric Gastroenterology, Hepatology, and Nutrition (ESPGHAN). J Pediatr Gastroenterol Nutr 2009;49(4):498-547.

22. Baikie G, South MJ, Reddihough DS, Cook DJ, Cameron DJ, Olinsky A, Ferguson E. Agreement of aspiration tests using barium videofluoroscopy, salivagram, and milk scan in children with cerebral palsy. Dev Med Child Neurol 2005;47(2):86-93.

23. Tzeng AC, Bach JR. Prevention of pulmonary morbidity for patients with neuromuscular disease. Chest 2000;118(5):1390-1396.

24. Kraemer R, Latzin P, Pramana I, Ballinari P, Gallati S, Frey U. Long-term gas exchange characteristics as markers of deterioration in patients with cystic fibrosis. Respir Res 2009;10:106.

25. McKenzie SA, Bridge PD, Pao CS. Lung function tests for preschool children. Paediatr Respir Rev 2001;2(1):37-45.

26. Verhulst SL, Schrauwen N, Haentjens D, Van Gaal L, De Backer WA, Desager KN. Reference values for sleep-related respiratory variables in asymptomatic European children and adolescents. Pediatr Pulmonol 2007;42(2):159-167.

27. Young NL, Steele C, Fehlings D, Jutai J, Olmsted N, Williams JI. Use of health care among adults with chronic and complex physical disabilities of childhood. Disabil Rehabil 2005;27(23):14551460.
28. Del Giudice E, Staiano A, Capano G, Romano A, Florimonte L, Miele E, et al. Gastrointestinal manifestations in children with cerebral palsy. Brain Dev 1999;21(5):307-311.

29. Bozkurt M, Tutuncuoglu S, Serdaroglu G, Tekgul H, Aydogdu S. Gastroesophageal reflux in children with cerebral palsy: efficacy of cisapride. J Child Neurol 2004;19(12):973-976.

30. Pensabene L, Miele E, Del Giudice E, Strisciuglio C, Staiano A. Mechanisms of gastroesophageal reflux in children with sequelae of birth asphyxia. Brain Dev 2008;30(9):563-571.

31. Kubiak R, Spitz L, Kiely EM, Drake D, Pierro A. Effectiveness of fundoplication in early infancy. J Pediatr Surg 1999;34(2):295-299.

32. Diaz DM, Gibbons TE, Heiss K, Wulkan ML, Ricketts RR, Gold $\mathrm{BD}$, et al. Antireflux surgery outcomes in pediatric gastroesophageal reflux disease. Am J Gastroenterol 2005;100(8):1844-1852.

33. Tannuri AC, Tannuri U, Mathias AL, Velhote MC, Romão RL, Gonçalves ME, Cardoso S. Gastroesophageal reflux disease in children: efficacy of Nissen fundoplication in treating digestive and respiratory symptoms. Experience of a single center. Dis Esophagus 2008;21(8):746-750.

34. Bates ML, Farrell ET, Eldridge MW. Abnormal ventilatory responses in adults born prematurely. N Engl J Med 2014;370(6):584-585.

35. Gaultier C, Boulé M, Allaire Y, Clément A, Buvry A, Girard F. Determination of capillary oxygen tension in infants and children: assessment of methodology and normal values during growth. Bull Eur Physiopathol Respir 1979;14(3):287-297. 